\title{
sciforum
}

Conference Proceedings Paper

\section{Patterns of atmospheric moisture transport linked to Southern Ocean Sea ice coverage changes}

\author{
Raquel Nieto ${ }^{1,2 *}$, Rosmeri P. da Rocha ${ }^{2}$, Luis Gimeno-Sotelo ${ }^{1}$, Marta Vázquez ${ }^{1}$, Lucía Losada ${ }^{1}$ \\ and Luis Gimeno ${ }^{1}$ \\ Published: 10/11/2017 \\ Academic Editor: Francina Dominguez \\ 1 Environmental Physics Laboratory (EPhysLab), Facultade de Ciencias, Universidade de Vigo, Ourense \\ 32004, Spain; rnieto@uvigo.es (R.N.); 1.gimeno@uvigo.es (L.G.); martavazquez@uvigo.es (M.V.); \\ lucialosadar@gmail.com (L.L.); themrgimeno@hotmail.es (L.G.S.) \\ 2 Departmento of Atmospheric Sciences, Institute of Astronomy, Geophysics Atmospheric Sciences, \\ Universitu of Sao Paulo 05508-090, Brazil: rosmerir.rocha@iag.usp.br (R.P.R.) \\ * Correspondence: rnieto@uvigo.es
}

\begin{abstract}
Moisture sources identification and Sea Ice Concentration (SIC) were calculated for the period 1980-2016 for the Southern Ocean Sea. Five sectors of the Southern Ocean Sea (King Hakon VII, East Antarctic, Ross/Amundsen, Amundsen and Bellingshausen, Weddell) were selected to calculate their moisture sources. The results show that the most important moisture sources (calculated as positive values of Evaporation minus Precipitation, E-P>0) for these five seas come from extratropical latitudes in the storm track trajectories. The main moisture sources and affected regional seas are: Southern Australia (SAUS) moisture source which affect mainly Ross/Amundsen and Amundsen and Bellingshausen seas; the Atlantic Ocean is the main source of moisture for Weddell and King Hakon VII; and the Pacific Ocean provides moisture to Ross/Amundsen, Weddell and Amundsen and Bellingshausen seas. For most of these seas it was identified positive trends of $\mathrm{E}-\mathrm{P}>0$ anomalies, while negative trends were identified only for the SAUS moisture source to Amundsen and Bellingshausen Sea. In terms of SIC, for the whole Antarctic the total anomalies are increasing, but no breaking points in this time serie were detected. Preliminary results also indicate some areas, which do not coincide exactly with the limit of the regional seas, where the increase of Sea Ice Extension (SIE) is statistically significant.
\end{abstract}

Keywords: Moiture sources; Southern Ocean Sea; Sea Ice Extension; Lagrangian analysis.

\section{Introduction}

In contrast to the Arctic, where an important reduction in sea ice has occurred in the last three decades, the global Southern Ocean Sea ice coverage has been moderately increasing. This trend is dominated by the positive trend in western Ross Sea and mitigated by the negative trend in other regions such as the Amundsen Sea [1]. Among the multiple atmospheric and oceanic drivers controlling the ice changes, little attention has been paid to variations in the transport of moisture from the extratropics, a mechanism proposed to have an important role on the Arctic atmospheric hydrological system [e.g., 2], with implications for the Arctic Sea ice extension. 
The 1st International Electronic Conference on Hydrological Cycle (CHyCle-2017), 12 - 16 November 2017; Sciforum Electronic Conference Series, Vol. 1, 2017

We analyze the moisture transport towards global Southern Ocean and individual Seas with different ice cover trends for the period 1980-2016. To this end, we applied the Lagrangian FLEXible PARTicle dispersion (FLEXPART) model to 1) identify main moisture sources at a monthly and seasonal basis, 2) study the transport of moisture from the sources to the target regions over the Southern Ocean, including annual trends and seasonal cycles. The following steps are i) check if there has been any change in the moisture transport before and after breakpoints in the annual series of Southern Ocean Sea Ice, if any, and ii) study the frequency of both Lagrangian moisture transport patterns and circulation patterns to estimate the probability distributions of Sea Ice extension (SIE) variability driven by the atmospheric circulation and moisture transport.

\section{Experiments}

\subsection{Areas of study and Sea Ice Concentratio Data.}

Sea ice change and variability are often described in terms of Sea Ice Extent (SIE), which is the total area of sea ice coverage with a Sea Ice Concentration (SIC) greater than some threshold value (typically 15\%). SIE can be calculated over a range of domains: the total circumpolar region, or specific sectors. Raphael and Hobbs [3] proposed the following sector boundaries according to standard deviation of SIE (see Figure 1): King Hakon VII $\left(20^{\circ} \mathrm{W}-70^{\circ} \mathrm{E}\right)$, East Antarctic $\left(70-163^{\circ} \mathrm{E}\right)$, Ross/Amundsen $\left(163-250^{\circ} \mathrm{E}\right)$, Amundsen and Bellingshausen $\left(250-293^{\circ} \mathrm{E}\right)$, and Weddell $\left(293^{\circ} \mathrm{E}-\right.$ $\left.360^{\circ} \mathrm{E}\right)$.

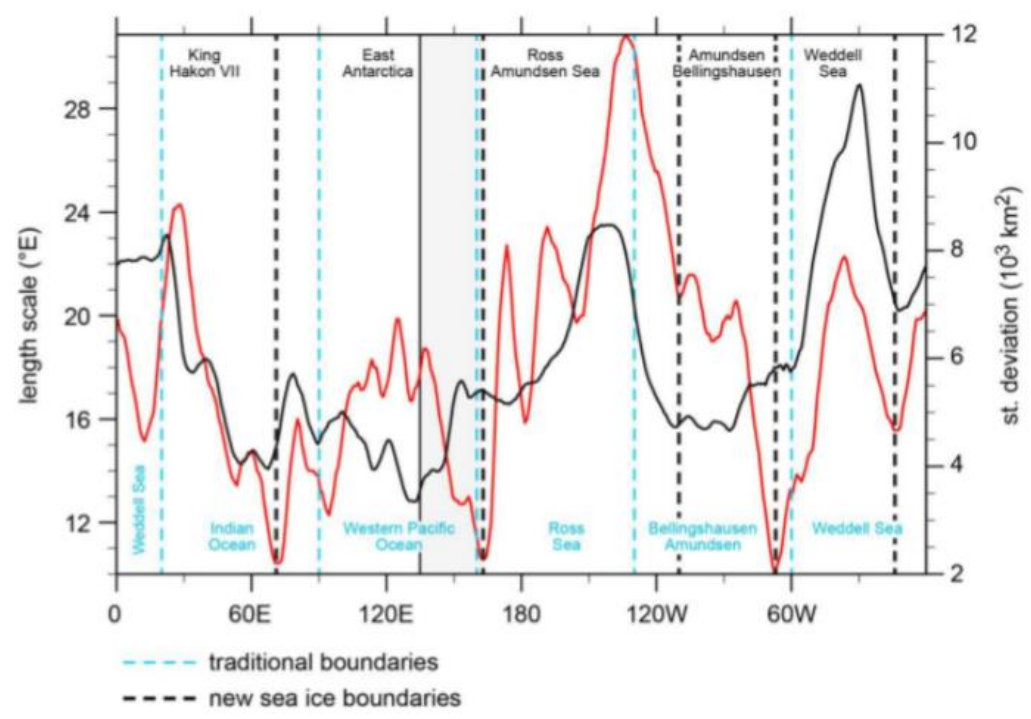

Figure 1. Standard deviation of sea ice anomalies by longitude (black) and decorrelation length scale (red). New sea ice boundaries (dashed black lines); traditional boundaries [4] (dashed blue lines). The grey shaded region is a zone where the new sea ice boundary between East Antarctica and Ross-Amundsen sector is uncertain. Source: Raphael and Hobbs (2014) [3].

For these regions SIC trend are analyzed for the period 1979-2016. SIC is a pixel/grid-scale observation defined as the fraction of ocean area covered by sea ice. It is the core sea ice observation derived from satellite passive microwave data from which most other metrics are derived. The spatial and seasonal SIC used in this work is based on the NASA Goddard-merged parameter in the NOAA/NSIDC Climate Data Record (CDR) product [5]. The first step in this work was to update the 1979-2014 trends of SIC by season to 2016 (the last data available). 
The 1st International Electronic Conference on Hydrological Cycle (CHyCle-2017), 12 - 16 November 2017; Sciforum Electronic Conference Series, Vol. 1, 2017

\subsection{Lagrangian tracking - FLEXPART}

We used FLEXPART v9.0 model [6,7] as a Lagrangian approach to analyze the moisture sources. This model divided the atmosphere homogenously into nearly 2.0 million particles to track individual trajectories representing air movement. It can move the particles backward or forward in time using a 3D wind field. The latitude, longitude, and altitude, and specific humidity (q) are recorded every 6 hours. In every time step it is possible calculate for each particle changes in moisture through the difference between the precipitation (p) and the evaporation (e). This changes in time along the individual trajectories follow this equation:

$$
e-p=m \frac{d q}{d t}
$$

This $(\mathrm{e}-\mathrm{p})$ values represent the freshwater flux associated with the particl, and adding it in an atmospheric column over a given area for all the particles residing in it, it is possible to calculate (E $\mathrm{P})$, the surface freshwater associated with that particles. $\mathrm{E}$ and $\mathrm{P}$ are the rates of evaporation and precipitation per unit area.

For the FLEXPART experiment we used ERA-Interim reanalysis [8], available at $6 \mathrm{~h}$ intervals with $1^{\circ}$ spatial resolution on 61 vertical levels, from 1000 to $0.1 \mathrm{hPa}$.

For the five individual seas considered in this study the Lagrangian approach was used to analyze the major oceanic sources based on FLEXPART, forced by global reanalysis data ERA-Interim, considering a 37-year period from January 1980 to December 2016. FLEXPART can be used in backward mode to determine the sources of moisture for given area, or in its forward mode to investigate the moisture transport of particles from their sources [9]. In this study, both options were applied in this order.

As a first step, moisture sources for the five individual seas of the Southern Ocean Sea domain were located using the backward mode. The SIE is different along the year and an area selection was done to delimit each area by month for each individual sea. With this in mind all particles residing over each domain (the target regions) were tracked backward during 10 days to assess where the particles gained moisture. The period of tracking was limited to 10 days (i10) since this is the average residence time of water vapor in the atmosphere [10]. The total atmospheric moisture budget $(\mathrm{E}-\mathrm{P})$ integrated over the 10 days of tracking (i10) and averaged over the period of interest (annual or seasonal), hereafter namely $(\mathrm{E}-\mathrm{P}) \mathrm{i} 10$, shows where the particles acquired or lost moisture before reaching the target areas. Where $(\mathrm{E}-\mathrm{P}) \mathrm{i} 10>0$ the air parcels over that area gain moisture from the atmosphere, and where $(\mathrm{E}-\mathrm{P}) \mathrm{i} 10<0$ they lose moisture to the atmosphere. As we are interested in the source of moisture we kept only positive values: $(\mathrm{E}-\mathrm{P}) \mathrm{i} 10>0$. Annual and seasonal sources were selected, considering austral summer as December-January-February (DJF); austral autumn as March-AprilMay (MAM); austral winter as June-July-August (JJA); and austral spring as September-OctoberNovember (SON).

The major sources of moisture for each individual seas were defined as those areas with a moisture uptake greater than the threshold that represents the 75th percentile on the annual backward values of positive (E - P)i10. Once the main moisture sources are identified using the annual climatology, a forward analysis was applied using these sources in order to analyze the moisture contribution of each source to each target region for $(\mathrm{E}-\mathrm{P}) \mathrm{i} 10<0$. In this case, particles from each source region were tracked forward during 10 days to quantify the moisture lost over the target areas, and to characterize annual, seasonal or daily cycles and their possible trends (if any). 
The 1st International Electronic Conference on Hydrological Cycle (CHyCle-2017), 12 - 16 November 2017; Sciforum Electronic Conference Series, Vol. 1, 2017

\section{Results and Discussion}

Figure 2 and 3 shows the seasonal and annual values of the 10 days integrated atmospheric moisture budget $(\mathrm{E}-\mathrm{P}) \mathrm{i10}>0$, respectively, obtained using the backward trajectories from our five target areas. The sources of moisture for the region of interest are identified in Figure 3 as those areas with positive values in the (E - P)i10 fields. The main moisture sources are located over the extratropical latitudes of Southern Oceans in the belt known as "storm track", where extratropical cyclones are moving from west to east during all months of the year. During austral winter and spring seasons it is noted an intensification of moisture sources, mainly in Atlantic and Southern Australia (Figure 2).

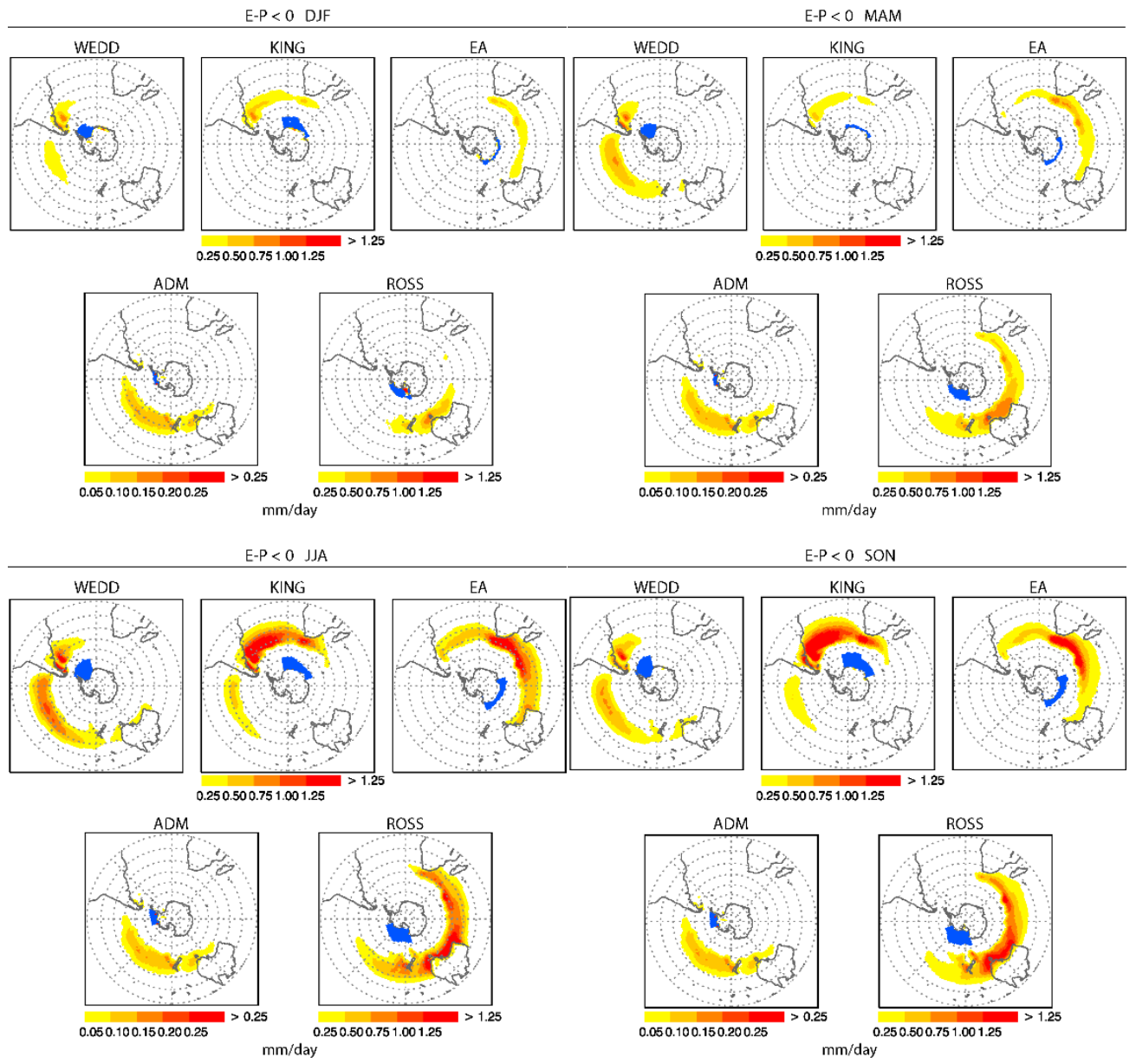

Figure 2. Seasonal climatology of 10 days integrated (E- P) $>0$ values for the period 1980 2016, for all the particles bound for each individual seas of the Southern Ocean, determined from backward tracking. Red colors represent moisture sources. In blue is the SIE for the middle month of the season. 
The 1st International Electronic Conference on Hydrological Cycle (CHyCle-2017), 12 - 16 November 2017; Sciforum Electronic Conference Series, Vol. 1, 2017

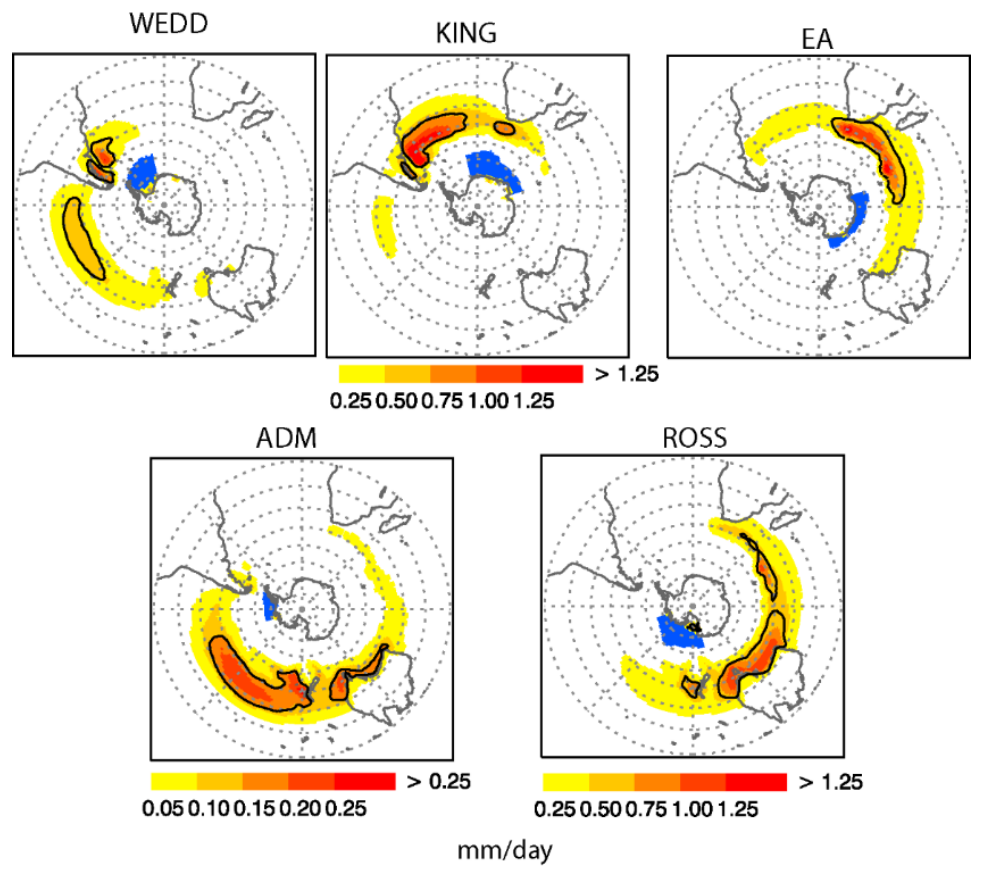

Figure 3. Annual climatology of 10 days integrated (E- P) $>0$ values for the period 1980 2016, for all the particles bound for each individual seas of the Southern Ocean, determined from backward tracking. Red colors represent moisture sources. In blue is the SIE for September. The black line marks the threshold that represents the 75th percentile of the (E$\mathrm{P})>0$ field for each individual sea.

From Figure 3, we named the moisture source regions as: Pacific Ocean (PAC), Southern Australia (SAUS) and Atlantic Ocean (ATL). With the sources of moisture defined, all the particles that leave these sources were forward runned to compute monthly (E-P)i10 $>0$ series, and also their anomalies and possible trends. Figure 4, for instance, presents the time series of monthly values of E$\mathrm{P}<0$ (from January 1980 to December 2016, 444 months) of the moisture lost over the Ross/Amundsen Seas from its sources over PAC and SAUS.
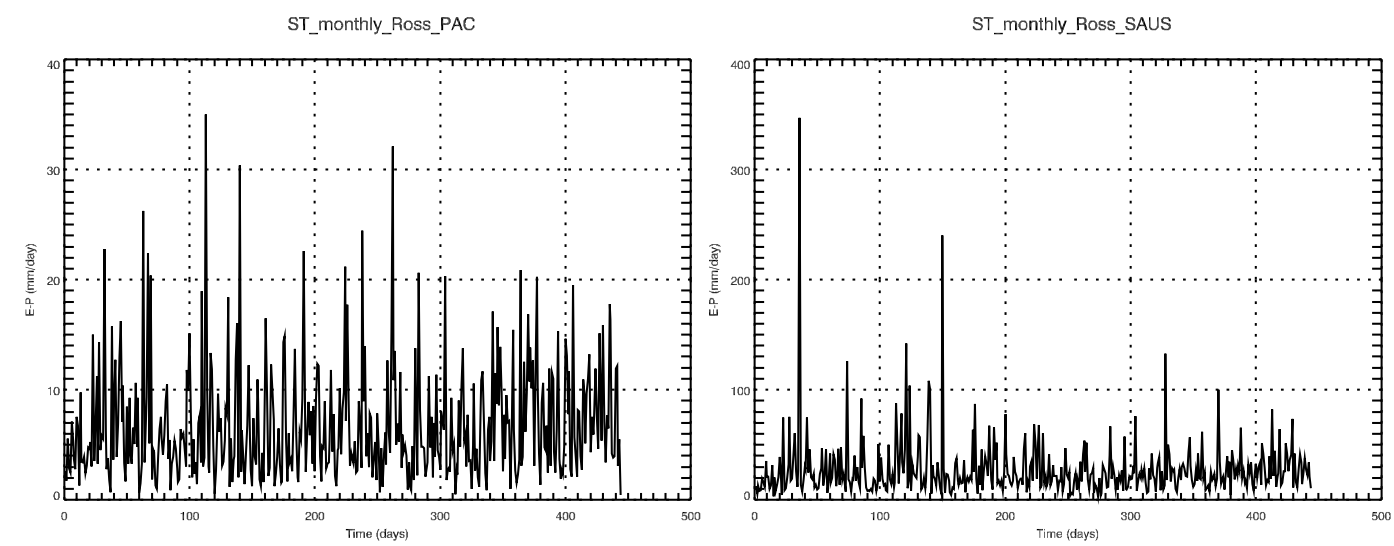

Figure 4. Time series of monthly values of E-P $<0$ (from January 1980 to December 2016, 444 months) of the moisture lost over the Ross/Amundsen Sea from its sources over the Pacific Ocean (PAC - left) and Southern Australia region (SAUS - right).

Monthly E-P $<0$ series for the remaining seas are shown on Figure 5 (Weddell Sea for ATL and PAC sources), Figure 6 (Amundsen/Belligshaussen for PAC and SAUS sources) and Figure 7 (King Hakon VII and East Antarctica Seas). 
The 1st International Electronic Conference on Hydrological Cycle (CHyCle-2017), 12 - 16 November 2017; Sciforum Electronic Conference Series, Vol. 1, 2017
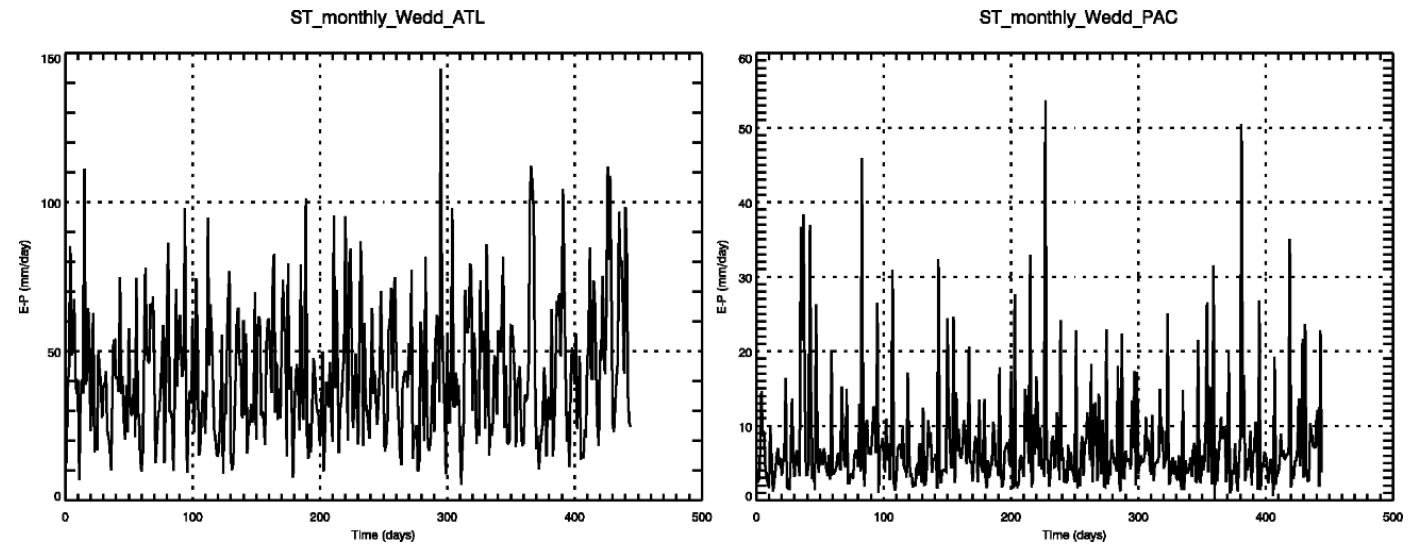

Figure 5. Similar to Figure 4, but for Weddell Sea and Atlantic (left) and Pacific sources (right).
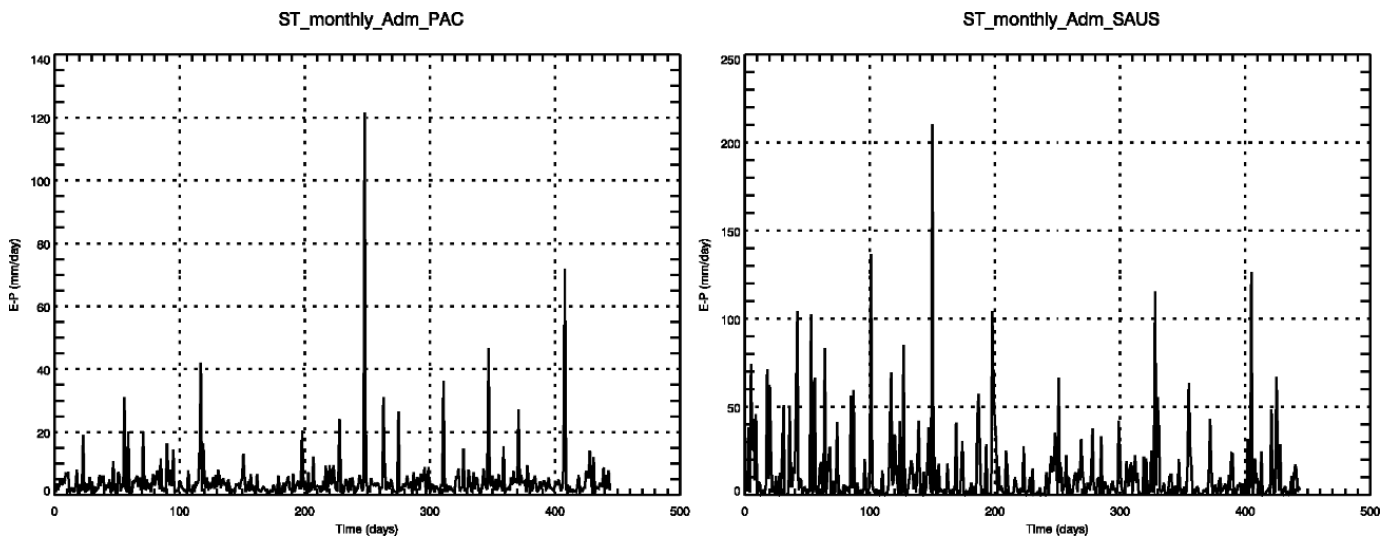

Figure 6. Similar to Figure 4, but for Amundsen/Bellingshausen Seas and Pacific (left) and Southern Australia region (SAUS - right) sources.
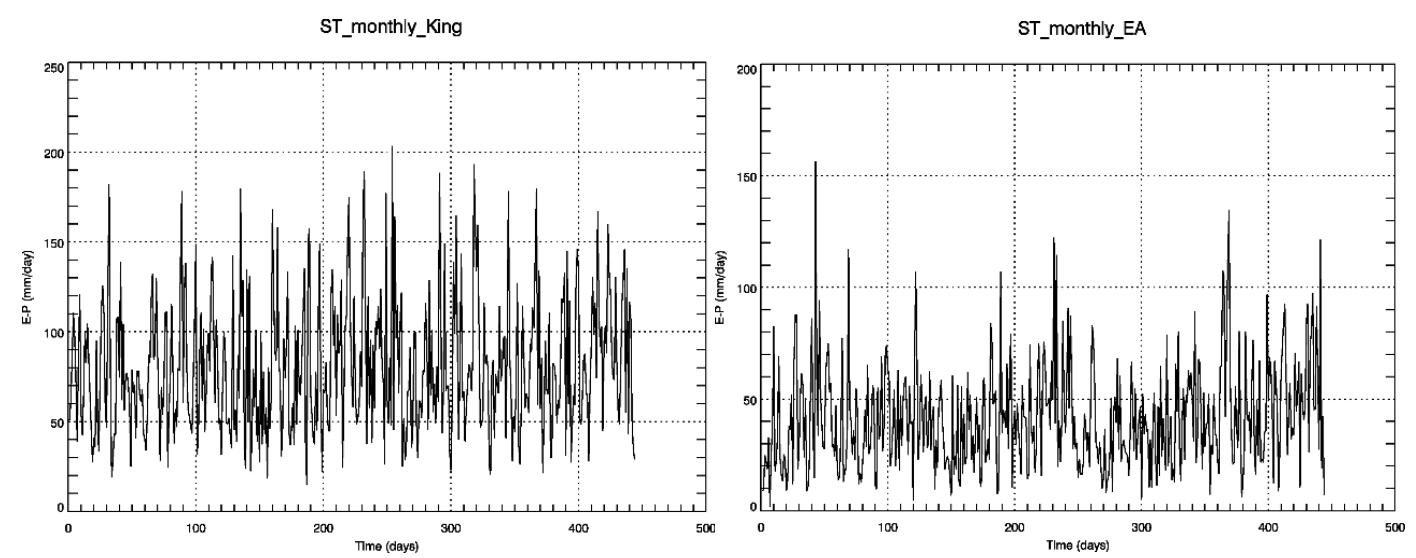

Figure 7. Time series of monthly values of E-P<0 (from January 1980 to December 2016, 444 months) of the moisture lost over the King Hakon VII and East Antarctica seas and their moisture sources, respectively, in South Atlantic (left) and Pacific (right).

All the sinks of moisture show a positive significant anomaly trend of (E-P)i10 $<0$ that comes from their sources, for instance see Figures 8a-b for East Antarctica and King Hakon VII Seas. Only for the (E-P)i10<0 from the SAUS source for the Amundsen and Bellingshausen Seas a significant negative trend is observed (Figure 8c). 
The 1st International Electronic Conference on Hydrological Cycle (CHyCle-2017), 12 - 16 November 2017; Sciforum Electronic Conference Series, Vol. 1, 2017
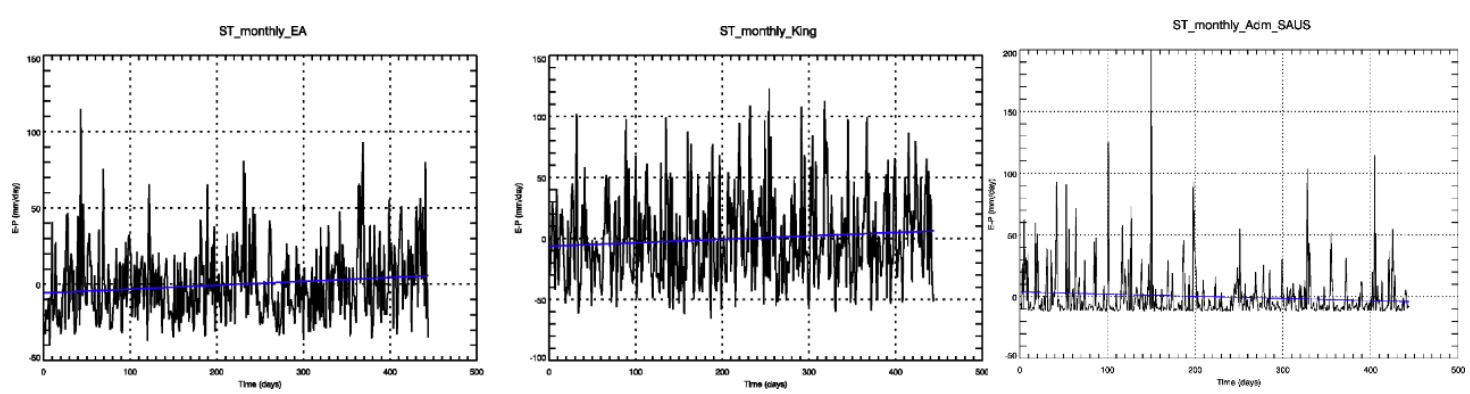

Figure 8. Time series of monthly values of E-P<0 (from January 1980 to December 2016, 444 months) for King Hakon VII, East Antarctica and Amundsen/Bellingshausen seas with the inclusion of linear trends (blue line).

Figure 9 shows the SIC trends during the austral summer (DJF, left-top) and during autral winter (JJA, left-bottom), and the significant trends (right plots). The results show that during austral summer and autumn (not shown) the largest trends are positive in the Weddell and western Ross Seas and negative in the Amundsen and Bellingshausen seas (ABS), which is in concordance with previous studies [1, 11,12]. In winter (JJA) and spring (not shown), the statistically significant trends occur near the ice edge of the Ross Sea, with a decrease in the Bellingshausen Sea along the western coast of the Antarctic Peninsula. We also verified that the sea ice coverage is higher during winter and spring, especially during September.
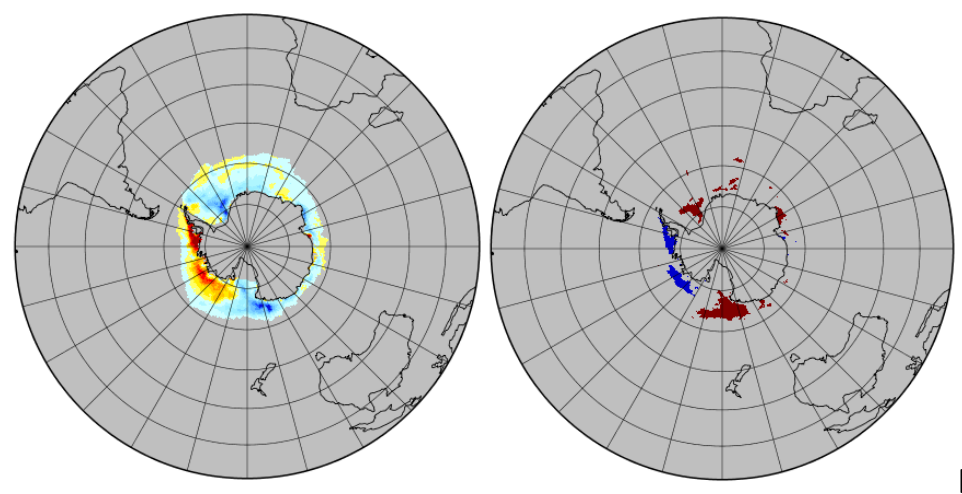

DJF
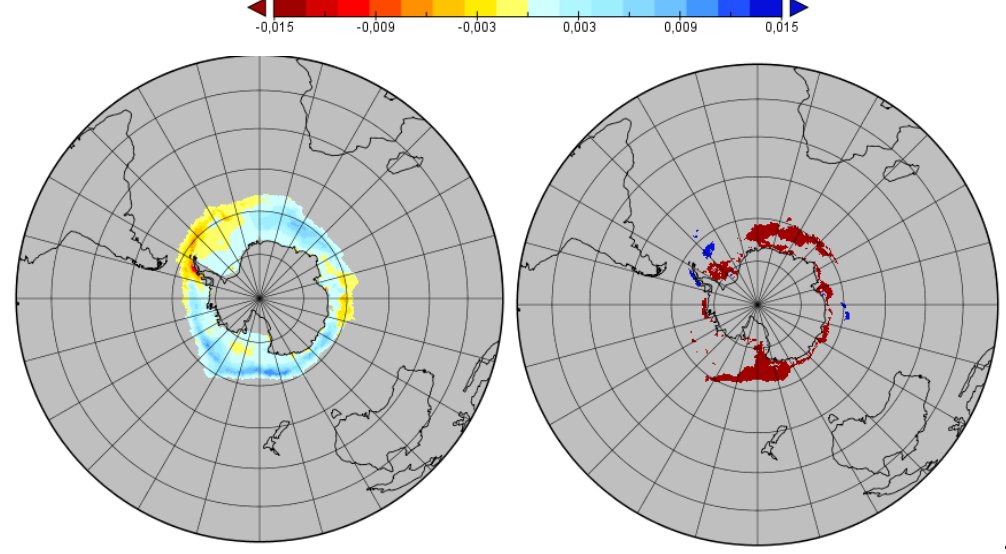

JJA

Figure 9. Left: 1979-2016 SIE trends. Right: red and blue shaded regions show, respectively, positive and negative SIE trends that are significant at the 95\% level. Top panel is for DJF and bottom panel is for JJA. Data from: NOAA/NSIDC Goddard-merged CDR monthly mean SIC product. 
The 1st International Electronic Conference on Hydrological Cycle (CHyCle-2017), 12 - 16 November 2017; Sciforum Electronic Conference Series, Vol. 1, 2017

As we commented, the Amundsen and Bellingshausen Seas is the unique large area where significant negative trends are observed in SIE and in (E-P)i10 $>0$; for the remaining series all of them show positive significant trends for both series.

\section{Conclusions}

For the period 1980-2016, moisture sources were calculated for the five sectors of Antarctic Sea (King Hakon VII, East Antarctic, Ross/Amundsen, Amundsen and Bellingshausen, Weddell) on seasonal and annual basis. The most important moisture sources for these seas are midlatitude zones in "storm tracks" trajectories. The moisture sources intensify during austral winter and spring. From the annual mean it was identified that Southern Australia (SAUS) moisture sources affect mainly Ross/Amundsen and Amundsen and Bellingshausen Seas, while the Atlantic Ocean is the main source of moisture for Weddell and King Hakon VII. The Pacific Ocean provides moisture to Ross/Amundsen, Weddell and Amundsen and Bellingshausen seas.

In terms of trends, Antarctic sea ice extension has grown during the last decades. Our first results indicate some areas, which do not coincide exactly with the limit of the regional seas, where the increase is statistically significant. Also over the whole Antarctic the total SIE anomalies are increasing.

Over the mayority sinks of moisture over the Antarctic individual seas we can observed positive and significant trends for SIE and (E-P)i10>0 monthly time series; only for the region Amundsen and Bellingshausen significant negative trends are observed for both series.

A more detailed analysis is being performance in order to complete these results. We are currently working in the calculation of the existence of breakpoints in the monthly SIE anomalies for the individual seas to evaluate the changes in moisture transport before and after the breakpoints if they exist. Statistical significance of the differences will be estimated by comparing monthly values of moisture transport before and after the breakpoint, if the size of the samples is big enough to permit a Student $\mathrm{t}$-test. Circulation patterns associated with both periods will also be analyzed.

Acknowledgments: L.G. and R.P.R. thanks to the FAPESP 2017/03981-3 project. This research was also partially supported by Xunta de Galicia under project ED413C 2017/64 "Programa de Consolidacion e Estructuracion de Unidades de Investigacion Competitivas (Grupos de Referencia Competitiva)" co-funded by European Regional Development Fund (FEDER).

Author Contributions: G.P., R.N. and R.P.R. conceived and designed the experiments; R.N., M.V., L.L. and L.G.S. performed the experiments; R.N. and L.G. analyzed the data; R.N. and R.P.R. wrote the paper.

Conflicts of Interest: The authors declare no conflict of interest.

\section{Abbreviations}

FLEXPART: FLEXible PARTicle dispersion

SIE: Sea Ice Extent

SIC: Sea Ice Concentration

CDR: Climate Data Record

E: Evaporation

P: Precipitation

DJF: December-January-February

MAM: March-April-May

JJA: June-July-August

SON: September-October-November 
The 1st International Electronic Conference on Hydrological Cycle (CHyCle-2017), 12 - 16 November 2017;

Sciforum Electronic Conference Series, Vol. 1, 2017

ABS: Amundsen and Bellingshausen seas

PAC: Pacific Ocean

SAUS: Southern Australia

ATL: Atlantic Ocean

\section{References}

1. Hobbs, W.R. et al. A review of recent changes in Southern Ocean sea ice, their drivers and forcings. Glob. Planet. Change 2016, 143, 228-250, doi:10.1016/j.gloplacha.2016.06.008.

2. Gimeno, L.; Vázquez, M.; Nieto, R.; Trigo, R.M. Atmospheric moisture transport: the bridge between ocean evaporation and Arctic ice melting. Earth Syst. Dynam. 2015, 6, 583-589, doi:10.5194/esd-6-583-2015.

3. Raphael, M.N.; Hobbs, W. The influence of the large-scale atmospheric circulation on Antarctic sea ice during ice advance and retreat seasons. Geophys. Res. Lett. 2014, 41, 5037-5045, doi:10.1002/2014GL060365.

4. Parkinson, C.L.; Cavalieri, D.J. Antarctic sea ice variability and trends, 1979-2010. The Cryosphere 2012, 6, 871-880, doi:10.5194/tc-6-871-2012.

5. Meier, W.; Fetterer, F.; Savoie, M.; Mallory, S.; Duerr, R.; Stroeve, J. NOAA/NSIDC Climate Data Record of passive microwave sea ice concentration, version 2. 2013 doi: 10.7265/N55M63M1.

6. Stohl, A.; James, P. A Lagrangian analysis of the atmospheric branch of the global water cycle. Part 1: Method description, validation, and demonstration for the August 2002 flooding in central Europe. J. Hydrometeor. 2004, 5, 656-678, doi:10.1175/1525-7541(2004)005<0656:ALAOTA>2.0.CO;2.

7. Stohl, A.; James, P. A Lagrangian Analysis of the Atmospheric Branch of the Global Water Cycle. Part II: Moisture Transports between Earth's Ocean Basins and River Catchments. J. Hydrometeorol. 2005, 6, 961984. doi: https://doi.org/10.1175/JHM470.1.

8. Dee, D.P.; Uppala, S.M.; Simmons, A.J.; Berrisford, P.; Poli, P.; et al. The ERA Interim reanalysis: Configuration and performance of the data assimilation system. Q. J. Roy. Meteorol. Soc. 2011, 137, 553-597, doi:10.1002/qj.828.

9. Stohl, A.; Forster, C.; Frank, A.; Seibert, P.; Wotawa, G. Technical note: the Lagrangian particle dispersion model FLEXPART version 6.2. Atmos. Chem. Phys. 2005, 5, 2461-2474, doi:10.5194/acp-5-2461-2005.

10. Numaguti, A. Origin and recycling processes of precipitating water over the Eurasian continent: Experiments using an atmospheric general circulation model. J. Geophys. Res. 1999, 104, 1957-1972, doi: 10.1029/1998JD200026.

11. Liu, J.; Curry, J.A.; Martinson, D.G. Interpretation of recent Antarctic sea ice variability. Geophys. Res. Lett. 2004, 31, L02205, doi: 10.1029/2003GL018732.

12. Holland, P.R. The seasonality of Antarctic sea ice trends. Geophys. Res. Lett. 2014, 41, 4230-4237, doi:10.1002/2014GL060172.

(c) 2017 by the authors; licensee MDPI, Basel, Switzerland. This article is an open access article distributed under the terms and conditions of the Creative Commons by Attribution (CC-BY) license (http://creativecommons.org/licenses/by/4.0/). 